\title{
Violent Asphyxial Death: A Study in Dinajpur Medical College, Dinajpur
}

\author{
Md. Mizanur Rahman ${ }^{1}$, Md. Rezaul Haque ${ }^{2}$, Polash Kumar Bose ${ }^{3}$
}

\begin{abstract}
Background: The word asphyxia is now commonly used to describe a range of conditions for which the lack of oxygen whether it is partial (hypoxia) or complete (anoxia) is considered to be the cause. The cardinal signs of asphyxia are cyanosis, congestion and petechial haemorrhage. Objective: To investigate the causes and manner of asphyxial death. Materials and Methods: It was a retrospective study conducted in the department of Forensic Medicine, Dinajpur Medical College, Dinajpur during July 2004 to June 2006. A total of 96 cases were examined and recorded. These cases were brought to the morgue of Dinajpur Medical College from 13 different police stations and 1 railway GRP station of Dinajpur district. The data were collected from the autopsy reports (preserved third copy) with permission of the concerned autopsy surgeons. Results: $88.55 \%$ of asphyxia deaths were due to hanging, $6.25 \%$ due to strangulation and $5.20 \%$ were due to suffocation. Conclusion: Most of the asphyxial deaths are due to hanging.
\end{abstract}

Keywords: Anoxia, Violent asphyxia, Hanging, Strangulation, Suffocation

J Enam Med Col 2013; 3(2): 91-93

\section{Introduction}

Asphyxia is a condition caused by interference with respiration or due to lack of oxygen in inspired air due to which the organs and tissues are deprived of oxygen causing unconsciousness or death. The classical features of asphyxia are found when the air passage is constricted by pressure applied to the neck or to the chest and when there has been struggle to breathe. ${ }^{1}$ In forensic context, asphyxia is usually obstructive in nature, where some physical barrier prevents access of air to lung. This obstruction can occur at any point from the nose and mouth to the alveolar membranes, other conditions in which the body cannot gain sufficient oxygen may occur without any obstruction to the cells of the body. It is now surprising that clinical and pathological features of many different types of asphyxia vary. ${ }^{2}$ Nervous tissues are affected first by deficiency of oxygen and their functions are disturbed even by mild oxygen deficiency. Sub-normal oxygen in the blood supply to the brain causes rapid unconsciousness. In all forms of asphyxia heart may continue to beat for several minutes after stoppage of respiration. The types of asphyxia may be mechanical, pathological, traumatic, environmental, positional and iatrogenic. In all types of asphyxia the air passages are blocked mechanically. In pathological asphyxia, the entry of oxygen to the lungs is prevented by diseases of the upper respiratory tract or of the lungs. In toxic asphyxia, poisonous substances prevent the use of oxygen and in the environmental asphyxia there is insufficiency of oxygen in inspired air.

Conventionally, the term asphyxia has been applied to all conditions in which oxygen supply to blood and tissue has been reduced appreciably below the normal working level by any interference with

1. Associate Professor, Department of Forensic Medicine, Enam Medical College, Savar, Dhaka

2. Professor, Department of Forensic Medicine, Enam Medical College, Savar, Dhaka

3. Assistant Professor, Department of Forensic Medicine, Enam Medical College, Savar, Dhaka

Correspondence Md. Mizanur Rahman, Phone: 01813-035383 
respiration. In death from asphyxia, usually it falls below the minimum necessary for continuance of life. Serious deprivation of oxygen for 5 to 10 minutes can result the permanent damage of CNS and CVS resulting death. It is interesting to note that in a healthy adult body, normally blood that is circulating has about one liter of oxygen held in combination. Any interference with this results in asphyxia which triggers the consequence.

Violent asphyxial deaths are common and may be classified as (1) hanging, (2) ligature strangulation, (3) throttling, (4) suffocation and (5) drowning. In forensic field, asphyxia is restricted to those forms of oxygen deficiency which result from mechanical interference with the process of respiration leading to anoxic anoxia. The traditionally accepted signs of asphyxia are due to pathological changes resulting from anoxia. The effects of anoxia on tissues is mainly two types - nonspecific and specific. As a result of nonspecific effects, body tissues undergo parenchymatous de-generation. As a result of specific effects, the following systemic changes are seen: cyanosis, increased capillary permeability and petechial haemorrhage. These signs develop when mechanical obstruction to breathing is maintained for about 15-30 seconds and a close look in a good light is necessary to notice cyanosis and Tardeus spots.

It has been found that the number of asphyxial deaths has been increasing continually in our country and asphyxial deaths are more common in middle age group and in those who are lagging behind socio-economically. In this study we aimed to find out the frequency of asphyxial deaths with their types and the socio-economic condition of the victims.

\section{Materials and Methods}

This retrospective study was carried out in the department of Forensic Medicine, Dinajpur Medical College from July 2004 to June 2006. During this period all the medico-legal cases were brought from 13 police stations and 1 railway police station of Dinajpur district. From these medicolegal cases asphyxial deaths were included for this study. The data were collected from the autopsy reports (preserved third copy) with permission of the concerned autopsy surgeons. The victims of asphyxial deaths were categorised according to their socioeconomic conditions and also according to types of asphyxia.

During autopsy, a V-shaped incision and a careful dissection of neck layer by layer, is essential. It is desirable to eviscerate cranial, thoracic and abdominal viscera so that the body is drained of blood. Such draining provides a clear field for study of neck organs and prevent artificial seepage of blood in soft tissues of neck. ${ }^{3}$ It must be remembered that asphyxial signs vary strikingly in fresh body only. They progressively disappear with lapse of time and the signs may disappear also as a result of putrefaction. ${ }^{4}$ Asphyxial death may be suicidal (hanging), homicidal (strangulation) and accidental. Homicidal hanging occurs in cases of judicial hanging (justifiable homicide) and lynching (nonjustifiable) where the circumstances are obvious. Suicidal strangulation is not common although instances have been known. Homicidal strangulation is a common form of murder. In fact, strangulation should be assumed to be homicide until the contrary is proven to be more likely under the circumstances. It cannot be emphasized too strongly that the neck findings of any of the nonspecific features such as congestion and petichae, without firm circumstantial or preferably physical evidence of mechanical obstruction of respiration, it is quite insufficient to warrant a speculative diagnosis of asphyxia. If such collateral evidence is not forthcoming then the cause of death must be left undetermined. ${ }^{3}$

Socioeconomic classification of the victims was done on the basis of monthly income. Victims of monthly income Tk. 15000/= only or above were defined upper class, middle class was defined having income Tk. $10000 /=$ to $15000 /=$ only per month and lower class was defined having income less than Tk. $10000 /=$ only per month.

The asphyxial deaths were categorized on the basis of inquest reports and pattern of ligature marks. When ligature mark was oblique, noncontinuous and high up in the neck, it was due to hanging; when ligature mark was transverse, circular, continuous and below the thyroid cartilage, it was strangulation. When there was lack of oxygen from obstruction of 
the air passages at the level of the nose and mouth, it was suffocation.

\section{Results}

Table I shows the frequency of asphyxial deaths in different socio-economic groups and Table II shows different types of death.

Table I: Frequency of asphyxial deaths in different socio-economic groups

\begin{tabular}{|l|c|c|}
\hline Class & Number & Percentage \\
\hline Upper & 12 & 12.5 \\
\hline Middle & 24 & 25.0 \\
\hline Lower & 60 & 62.5 \\
\hline
\end{tabular}

Table II: Different types of asphyxial death

\begin{tabular}{|l|c|c|}
\hline Types & Number & Percentage \\
\hline Hanging & 85 & 88.55 \\
Strangulation & 6 & 6.25 \\
Suffocation & 5 & 5.20 \\
\hline
\end{tabular}

\section{Discussion}

During autopsy, it is possible to study systematically in details the various structures those are important from a medico-legal point of view. Carotid Artery damage must be sought with care because of process of opening the vessel may destroy the torn area. A radiological study of the excised hyoidlarynx complex should be carried out if there is any suspension or suggestion of mechanical injury. Regarding opinion all deaths due to hanging is suicidal until it is otherwise proved. All deaths due to strangulation are homicidal. Accidental asphyxial deaths may often occur. Mesochiastic practice to get sexual gratification by partial asphyxiation by arranged strangulation may also lead to death due to strangulation where they fail to release the tie at the right moment. ${ }^{5}$

Asphyxiation occurs when a person's oxygen supply is cut-off and air is unable to reach the lungs and surrounding blood supply. Actually, there was no remarkable study of asphyxia death regarding their types in our country previously. In our study, hanging was about $45 \%$ and strangulation 3\%. These findings are comparable to that of bulletin of WHO regarding the methods of suicide ${ }^{6}$; international suicide and homicide pattern derived from the WHO mortality database. In Canada, $44.4 \%$ was hanging and $2.1 \%$ strangulation in 2002-2003. ${ }^{6}$ In Australia, 45.4\% hanging in 1998-2003 and strangulation $1.5 \%$ in the same period. ${ }^{6}$ In Argentina (R-A) hanging is $49.1 \%$ and strangulation $2.2 \%$ in $1997-2003 .{ }^{6}$ During the $21-$ year period from January 1984 to October 2004, there were 134 asphyxial deaths autopsied by the department of Forensic Medicine, Trakya University, Edirne, Turkey. The most frequent method of asphyxiation death was hanging (56 cases, $41.8 \%$ ), strangulation constituted $5.2 \%{ }^{7}$

In conclusion, deaths due to asphyxia are one of the most important causes in violence deaths. Determining the cause and manner of death is quite challenging. In our study we found that most of the asphyxia deaths were due to hanging.

\section{References}

1. Reddy KSN. Death and its causes. In: The essentials of forensic medicine \& toxicology. $28^{\text {th }}$ edn. Hyderabad: K. Suguna Devi, 2009: 110-115.

2. Simpson. Asphyxia. In: Simpson's forensic medicine. $12^{\text {th }}$ edn. London: Arnold, Odder Headline Group, 2003: 92-96.

3. Parikh CK. Death from asphyxia. In: Parikh's textbook of medical jurisprudence, forensic medicine and toxicology. $6^{\text {th }}$ edn. Delhi: CBS Publishers \& Distributors, 1999: 3.2-3.37.

4. Knight B. Suffocation and asphyxia. In: Forensic pathology. $2^{\text {nd }}$ edn. London: Arnold, Odder Headline Group, 1996: 348-352.

5. Nandy A. Violent asphyxial death. In: Principles of forensic medicine including toxicology. $2^{\text {nd }}$ edn. Kolkata: New central Book Agency (P) Ltd, 2000: 535-545,

6. Method of suicide: international suicide patterns derived from WHO mortality database. Available at: www.unece.org/trans/conventn/distsigns.pdf. Accessed December 2012.

7. Azmak D. Asphyxial deaths: a retrospective study and review of the literature. Am J Forensic Med Pathol 2006; 27(2): 134- 144. 